\title{
Characteristic Immune Abnormalities in Hemophagocytic Lymphohistiocytosis
}

\author{
R. Maarten Egeler, M.D., Ph.D., Ralph Shapiro, M.D., Brett Loechelt, M.D., \\ and Alexandra Filipovich, M.D.
}

\begin{abstract}
Purpose: Hemophagocytic lymphohistiocytosis (HLII) is a lifethreatening syndrome characterized by fiver, hepatosplenomegaly, pancytopenia, and infiltration of vital organs by non-Langerhans histiocytes and is rapidly fatal without carly diagnosis and institution of therapy. Immune dysregulation is thought to be responsible for the discase.
\end{abstract}

Patients and Methods: Extensive immune evaluation was performed on 13 consecutive patients diagnosed with HLH over a 4-ycar period to characterize existing immunologic abnormalities in order to improve early diagnosis. livaluation included quantitative immunoglobulins, immunophenotyping, mitogeninduced lymphoproliferation, natural killer (NK) cell function, and cytotoxic T cell lymphocytolysis (CTL).

Results: Immunoglobulin levels showed no consistent abnormality. Immunophenotyping showed an absolute decrease in number of $B$ cells but normal numbers and proportional distribution of T cell subsets and NK cells. Most patients demonstrated decreased proliferative responses to mitogens $(10 / 13)$ and severely decreased to absent T eell cytotoxicity (11/12) and NK cytotoxic function $(13 / 13)$.

Conclusions: Our results show that while humoral immunity is essentially intact, cellular immune function is significantly impaired in the vast majority of patients with HLH. The coincident finding of profoundly decreased $T$ cell cytotoxicity along with absent NK cytotoxicity suggests that patients with active HLH may have global cytotoxic dysfunction. Since the majority of our patients were studied prior to starting therapy, we feel that these findings reflect the pathophysiologic process and are not therapy related. Unclear from the present work is whether these findings represent primary or secondary dysfunction. We conclude from these studies that profoundly decreased (TL function and absence of NK cell function are characteristic immunologic features of HLH and may serve as additional laboratory data, in conjunction with currently proposed diagnostic guidelines, to support a diagnosis of $\mathrm{HLH}$.

Submitted for publication February 0. 1995. Accepted Junc 4. 1996. From the Pediatric Immunology Department, University of Minnesota. Minneapolis, Minnesota, U.S.A.

Address correspondence and reprint requests to Dr. R. M. Egeler. Sophia Children's Hospital, Dr. Molewaterplein 60). 3015 (jJ Rotterdam. The Netherlands.

Dr. R. Shapiro's present address is Department of Pediatrics. Minneapolis Children's Hospital, Minneapolis, Minnesota, U.S.A.

Dr. B. Loechelt's present address is Department of Pediatrics, Children`s Medical Center, Washington. D.C... U.S.A.

Dr. A. Filipovich"s present address is Department of Pediatrics, University of Minnesota, Minneapolis, Minnesota, U.S.A.
Key Words: Hemophagocytic lymphohistiocytosis-Familial hemophagocytic lymphohistiocytosis-Familial erythrophagocytic lymphohistiocytosis Cytotoxic T cell- Natural killer cell.

Hemophagocytic lymphohistiocytosis (HLH) is a descriptive term applied to a life-threatening "hemodestructive" syndrome that occurs in several disorders, including an autosomal recessive inherited disease called familial hemophagocytic lymphohistiocytosis $(\mathrm{FHL})(1)$ and an acquired form termed viral-or infection-associated hemophagocytic syndrome (VAHS or IAHS) (2). Currently there are no conclusive clinical, laboratory, or histopathologic methods identified that may distinguish FHL from VAHS/IAHS in young children without a positive family history. The FHL Study Group of the Histiocyte Society has, for this reason, joined them under the general category of HLH. Clinical presentation of HLH consists of prolonged fever, failure to thrive, irritability, and hepatosplenomegaly. Associated laboratory features include pancytopenia, hypertriglyceridemia, and hypofibrinogenemia. The characteristic histopathologic finding is diffuse infiltration primarily of the liver, spleen, lymph nodes, and brain by activated non-Langerhans histiocytes actively phagocytizing blood cells. Without therapy, HLH is usually fatal with a median survival of only 2 months (3). Therapy including epipodophyllotoxin derivatives $(4,5)$ and/or immunosuppression (6) has been successful in controlling the disease. Early diagnosis and institution of therapy are essential for successful outcome.

Diagnosis of HLH is challenging since there is no specific diagnostic test for it. Guidelines to assist in making a diagnosis have recently been proposed based on clinical features with laboratory and histologic supporting data (7). Immune dysfunction is presently not included as an essential criterion, nor as supporting ev- 
idence for a diagnosis of HLH. While a variety of immune abnormalities have been reported in limited numbers of patients with HLH (8,9), little is known about the characteristic associated immune defects. For this reason, we prospectively performed comprehensive immune evaluation on a group of 13 consecutive patients.

\section{PATIENTS AND METHODS}

\section{Patients}

Included in this study were all patients evaluated at the University of Minnesota with a diagnosis of a hemophagocytic syndrome (VAHS/IAHS or FHL) from September 1988 until August 1992. The diagnosis was confirmed by the histopathologic and/or clinical and laboratory criteria provided by the FHL Study Group of the Histiocyte Society (7) (Table 1). All charts were subsequently reviewed and laboratory data confirmed for inclusion in this report.

\section{Methods}

\section{Immunoglobulin Studies}

The levels of $\operatorname{IgG}, \operatorname{IgA}, \lg \mathrm{M}$, and $\lg E$ were determined by standard methods in the hospital laboratory.

\section{Cell Surface Marker Studies}

Analysis of cell surface markers was performed by flow cytometry using standard techniques in the hospi-

TABLE 1. Diagnostic guidelines for hemophagocytic lymphohistiocytosis ${ }^{a}$

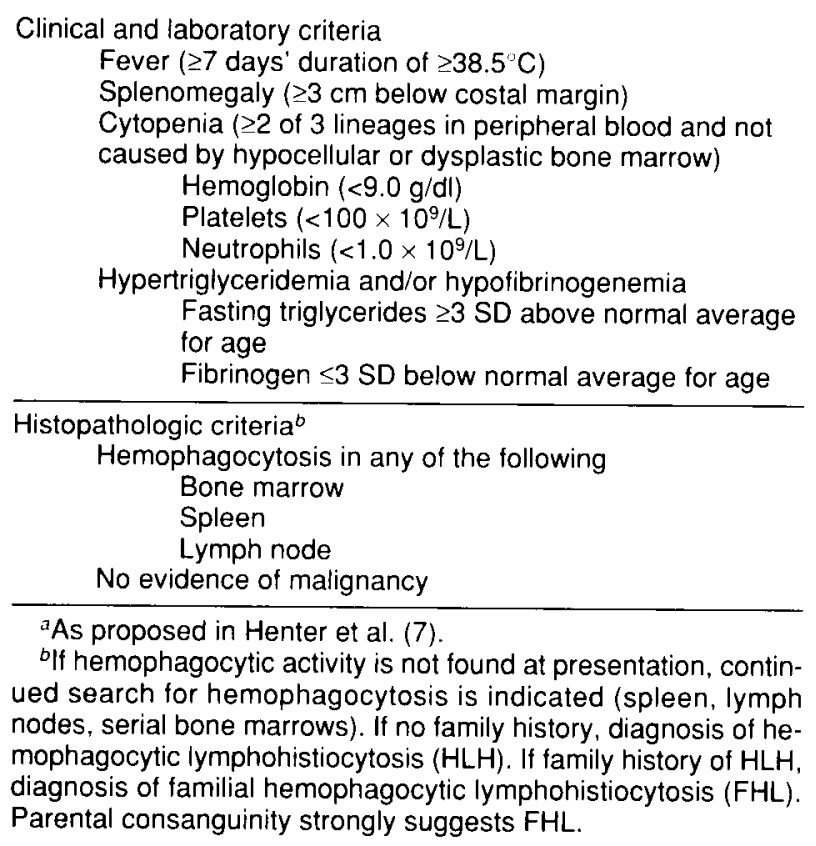

\footnotetext{
${ }^{a}$ As proposed in Henter et al. (7).

bif hemophagocytic activity is not found at presentation, continued search for hemophagocytosis is indicated (spleen, lymph nodes, serial bone marrows). If no family history, diagnosis of hemophagocytic lymphohistiocytosis (HLH). If family history of $\mathrm{HLH}$, diagnosis of familial hemophagocytic lymphohistiocytosis (FHL). Parental consanguinity strongly suggests FHL.
}

tal laboratory. Mononuclear cells were isolated from heparinized blood and were examined for the expression of cell surface antigens using monoclonal antibodies for subpopulations of $T$ cells, B cells, and natural killer (NK) cells: T11 (anti-CD2), T3 (anti-CD3), T4 (antiCD4), T8 (anti-CD8), B4 (anti-CD 19), NKH (antiCD56), and I3 (anti-DR) were obtained from Coulter Immunology (Hialcah, FL, U.S.A.); T101 (anti-CD5) and 3A-1 (anti-CD7) from T Cell Sciences (Cambridge, MA, U.S.A.); and Leu-1 IA (anti-CD16), Leu-7 (antiCD57), and WT31 (anti-TCT/CD3) from Becton Dickinson (Rutherford, NJ, U.S.A.). Age-adjusted normal ranges have been developed for $\mathrm{CD} 3^{\prime}, \mathrm{CD} 4^{+}, \mathrm{CD}^{+}$, CD $16^{\circ}$, and CD $19^{\prime}$ subsets.

\section{Limphocyte Proliferative Responses}

Peripheral blood mononuclear cells isolated by Ficoll-Hypaque centrifugation were placed in microtiter plates at a concentration of $1.5 \times 10^{6} \mathrm{cells} / \mathrm{ml}$ in RPMI 1640 with $10 \%$ pooled human serum. The standard mitogen battery consisted of phytohemagglutinin, conconavalin A, and pokeweed mitogen added at $10-200$, 12.5-500, and 6.25-50 $\mu \mathrm{g} / \mathrm{nl}$, respectively. Proliferation was assessed by the incorporation of $\left[{ }^{3} \mathrm{H}\right]$ thymidine, added $24 \mathrm{~h}$ prior to the end of $72 \mathrm{~h}$ of incubation at $37^{\circ} \mathrm{C}$ in $5 \% \mathrm{CO}_{2}$ atmosphere. Patient responses were calculated as a percent of the averaged responses of three normal adult controls tested simultaneously.

\section{Cytotoxic T Cell and NK Cell Activity,}

Major histocompatibility complex-restricted cytotoxic $T$ cell lymphocytolysis (CTL) activity was assayed after culture of $1.5 \times 10^{6}$ cells (effectors) in a nickel well containing $1.5 \times 10^{6}$ irradiated Epstein-Barr virus-transformed B lymphoblastoid cells (targets) in RPMI 1640 medium with $15 \%$ pooled human serum, $100 \mathrm{U} / \mathrm{ml}$ penicillin, $100 \mathrm{mg} / \mathrm{ml}$ streptomycin. $25 \mathrm{~m} M N$-2-hydroxyethylpiperazine- $N$ '-2-ethanesulfonic acid (Gibco, Grand Island, NY, U.S.A.), and $1 \mathrm{~m} M \mathrm{~L}-$ glutamine and incubated for 7 days at $37^{\circ} \mathrm{C}$ in a $5 \% \mathrm{CO}_{2}$ atmosphere. Effector cells were then centrifuged and washed. Targets were labeled for $1 \mathrm{~h}$ with $250 \mathrm{mCi}$ of ${ }^{51} \mathrm{Cr} / 2 \times 10^{6}$ cells, washed in cold medium with $15 \%$ pooled human serum, then diluted to a concentration of $4 \times 10^{4}$ cells $/ \mathrm{ml}$. Effectors were plated with targets at four dilutions at $50: 1$, $25: 1,12.5: 1$, and 6.25:1. Spontaneous lysis and maximal lysis were obtained by plating target cells with medium containing $15 \%$ pooled human serum and detergent H-5882 (Sigma, St. Louis, MO, U.S.A.), respectively. Plates were centrifuged at $500 \mathrm{rpm}$ for $3 \mathrm{~min}$ and then incubated for $4 \mathrm{~h}$ at $37^{\circ} \mathrm{C}$ in a $5 \% \mathrm{CO}_{2}$ atmosphere. They were then centrifuged for $10 \mathrm{~min}$ at 1,100 rpm, and supernatants from each well were analyzed 
using a gamma counter for quantification of ${ }^{51} \mathrm{Cr}$ release. Percent specific cytotoxicity was calculated by subtracting the mean counts per minute of spontaneous lysis from the mean counts per minute of each particular dilution divided by the mean counts per minute maximal lysis minus the mean counts per minute of spontaneous lysis.

The NK assay was set up in a manner similar to the CTL assay; however, the effector cells were not preincubated with the target cells. The targets for the NK assay were K562 leukemia cells. Normal controls of the day were set up with each patient sample for both CTL and NK assays. The normal ranges for these cytotoxic assays are listed in Table 3.

\section{RESULTS}

\section{Clinical Presentation}

All patients were previously in good health prior to developing symptoms related to the onset of hemophagocytic syndrome. Most presented with prolonged fever, progressive hepatosplenomegaly, and lethargy. Lymphadenopathy, rash, seizures, and failure to thrive were also presenting symptoms in some. None of the parents were consanguineous and five had family histories of HLH at the time of diagnosis. One has had a sibling develop HLH since completion of this study. Most patients met the established criteria for diagnosis of HLH; however, in three patients, hemophagocytosis by histopathology could not be demonstrated initially, yet they fit other diagnostic criteria (Table 2). Two of these, Patients 2 and 5, subsequently were found to have characteristic lymphohistiocytic infiltrates and hemophagocytosis at autopsy, confirming a diagnosis of HLH.

\section{Laboratory Features}

Table 2 shows the initial laboratory and histopathologic findings of the patients included in this study. All patients had cytopenia affecting at least two or three cell lineages. Thrombocytopenia was present in all, 12 of 13 had neutropenia, and 12 of 13 had anemia. All patients had hypertriglyceridemia and/or hypofibrinogenemia. Additionally, elevated transaminases were present in 12 of 13 patients and cerebrospinal fluid pleocytosis was found in 5 of 13 patients.

Histologic confirmation of hemophagocytosis was sought in each case. Bone marrow biopsy was performed as part of the diagnostic evaluation and revealed hemophagocytosis in $77 \%$. Eight patients had liver biopsies with four having evidence of hemophagocytosis. Lymph node biopsy was obtained in only two patients with one showing hemophagocytosis. No patient underwent splenic biopsy.

Immunological assessment was performed during diagnostic evaluation in each patient. Table 3 shows the results of the lymphocyte cell marker profiles, immunoglobulin levels, mitogen reactivity, cytotoxic $T$ lymphocyte activity, and NK cell function. White blood count was decreased in all but one patient primarily because of neutropenia. With the exception of two patients, the absolute lymphocyte counts were within normal range. All patients had normal $\mathrm{T}$ helper/T suppressor ratios $(\mathrm{CD} 4 / \mathrm{CD} 8)$. The number of NK cells, as determined by expression of CD16, CD56, and CD57, was also normal. Absolute $\mathrm{B}$ cell number as determined by CD 19 expression was decreased in 10 of 13 patients (normal absolute $\mathrm{CD} 19^{+} \mathrm{B}$ cell number at the University of Minnesota is $375-5,994 / \mathrm{mm}^{3}$ for $1-6$ months of age. $360-4,810 / \mathrm{mm}^{3}$ for $6-11$ months of age, and

TABLE 2. Characteristic findings in 13 patients diagnosed with hemophagocytic lymphohistiocytosis

\begin{tabular}{|c|c|c|c|c|c|c|c|c|c|c|c|c|c|c|}
\hline $\begin{array}{l}\text { Patient no. } \\
\text { Sex } \\
\text { Age (mos) }\end{array}$ & $\begin{array}{c}1 \\
M \\
6.5\end{array}$ & $\begin{array}{c}2 \\
F \\
1.5\end{array}$ & $\begin{array}{l}3 \\
F \\
4.0\end{array}$ & $\begin{array}{c}4 \\
M \\
24.0\end{array}$ & $\begin{array}{c}5 \\
F \\
2.0\end{array}$ & $\begin{array}{l}6 \\
F \\
8.0\end{array}$ & $\begin{array}{l}7 \\
F \\
8.0\end{array}$ & $\begin{array}{c}8 \\
M \\
3.0\end{array}$ & $\begin{array}{c}9 \\
F \\
3.0\end{array}$ & $\begin{array}{l}10 \\
F \\
3.0\end{array}$ & $\begin{array}{l}11 \\
\mathrm{~F} \\
7.0\end{array}$ & $\begin{array}{c}12 \\
\mathrm{M} \\
1.0\end{array}$ & $\begin{array}{c}13 \\
M \\
3.0\end{array}$ & $\begin{array}{c}\text { Total } \\
5 \mathrm{M} / 8 \mathrm{~F} \\
1.5-24\end{array}$ \\
\hline \multicolumn{15}{|l|}{ Laboratory criteria ${ }^{a}$} \\
\hline Hemoglobin $<9 \mathrm{~g} / \mathrm{d}$ & + & - & + & + & + & + & + & + & + & + & + & + & + & $12 / 13$ \\
\hline Platelets $<100 \times 10^{9} / \mathrm{L}$ & + & + & + & + & + & + & + & + & + & + & + & + & + & $13 / 13$ \\
\hline Neutrophils $<1 \times 10^{9} / \mathrm{L}$ & + & + & + & + & + & + & + & - & + & + & + & + & + & $12 / 13$ \\
\hline Hypertriglycerides & + & + & + & + & + & + & + & + & - & + & + & + & + & $12 / 13$ \\
\hline Hypofibrinogen & + & + & + & + & + & + & - & - & + & - & + & + & + & $10 / 13$ \\
\hline \multicolumn{15}{|l|}{ Histopathological criteria } \\
\hline Hemophagocytosis bone marrow & + & - & + & + & - & \pm & - & + & + & + & + & + & + & $10 / 13$ \\
\hline Hemophagocytosis spleen & ND & ND & ND & ND & ND & ND & ND & ND & ND & ND & ND & ND & ND & - \\
\hline Hemophagocytosis lymph nodes & ND & ND & ND & + & - & ND & ND & ND & ND & ND & ND & ND & ND & $1 / 2$ \\
\hline \multicolumn{15}{|l|}{ Supportive laboratory criteria } \\
\hline CSF (pleocytosis) & - & - & + & - & + & - & -- & + & - & + & - & - & + & $5 / 13$ \\
\hline Elevated transaminases & + & + & + & + & + & + & + & + & + & + & + & - & + & $12 / 13$ \\
\hline Hemophagocytosis liver ${ }^{b}$ & ND & + & + & ND & - & - & - & + & - & ND & + & ND & ND & $4 / 8$ \\
\hline
\end{tabular}

aDiagnostic guidelines according to the FHL Study Group (7).

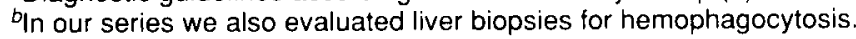


TABLE 3. Immunological markers in 13 patients with hemophagocytic lymphohistiocytosis

\begin{tabular}{|c|c|c|c|c|c|c|c|c|c|c|c|c|c|}
\hline Marker & \multicolumn{12}{|c|}{ Patient no. } & 13 \\
\hline WBC $\left(10^{9} / L\right)$ & 3.3 & 1.8 & 3.2 & 3.8 & 2.3 & 2.5 & 1.2 & 2.7 & 4.4 & 8.5 & 2.4 & 3.8 & 1.7 \\
\hline ALC $\left(10^{9} / \mathrm{L}\right)$ & 2.7 & 1.5 & 2.6 & 1.9 & 2.2 & 1.8 & 1.0 & 1.0 & 3.2 & 3.1 & 2.2 & 2.1 & 1.5 \\
\hline CD2 $(\%)$ & 93 & 95 & 82 & 76 & 98 & 94 & 87 & 95 & 89 & 97 & 89 & 97 & 73 \\
\hline CD3 $(\%)$ & 92 & 94 & 75 & 75 & 96 & 87 & 82 & 94 & 82 & 95 & 90 & 96 & 70 \\
\hline CD4 (\%) & 58 & 55 & 58 & 50 & 65 & 51 & 65 & 78 & 54 & 66 & 57 & 67 & 42 \\
\hline $\operatorname{CD5}(\%)$ & 93 & ND & 84 & 75 & 92 & 76 & 86 & 95 & 85 & 96 & 85 & 98 & 73 \\
\hline CD7 (\%) & 88 & ND & 74 & 79 & 94 & 85 & 79 & 95 & 83 & 99 & 67 & 94 & 73 \\
\hline $\operatorname{CD8}(\%)$ & 32 & 42 & 18 & 22 & 20 & 27 & 17 & 18 & 32 & 26 & 30 & 26 & 26 \\
\hline CD16 (\%) & 3 & ND & 4 & 5 & 3 & 6 & 5 & 2 & 7 & 3 & 5 & 1 & 7 \\
\hline CD19 (\%) & 10 & 3 & 12 & 22 & 1 & 6 & 16 & 2 & 17 & 3 & 61 & 1 & 26 \\
\hline CD56 (\%) & 3 & ND & 4 & 5 & 3 & 6 & 5 & 2 & 7 & 3 & 5 & 1 & 7 \\
\hline CD57 (\%) & 9 & ND & 27 & 11 & 7 & 13 & 5 & 3 & 11 & 2 & 10 & 1 & 3 \\
\hline $4 / 8$ ratio & 1.8 & 1.31 & 3.0 & 2.3 & 3.2 & 1.9 & 3.8 & 4.3 & 1.8 & 2.5 & 1.9 & 2.5 & 1.6 \\
\hline WT31 (\%) & 86 & ND & 66 & 70 & 90 & 81 & 81 & 95 & 81 & 96 & 89 & 97 & 67 \\
\hline HLA DR $(\%)$ & 30 & ND & ND & ND & ND & ND & ND & ND & ND & 1 & 26 & ND & 28 \\
\hline $\operatorname{lgA}(\mathrm{mg} / \mathrm{dl})$ & 67 & 7 & 18 & 17 & 78 & 238 & 61 & 45 & 43 & 27 & 21 & $<7$ & 71 \\
\hline $\lg E(k \mid U / L)$ & 11 & 4 & 49 & 15 & 21 & 130 & 115 & 2 & 34 & 9 & 17 & 2 & 40 \\
\hline $\lg G(\mathrm{mg} / \mathrm{d})$ & 250 & 297 & 766 & 617 & 1,010 & 605 & 895 & 451 & 275 & 519 & 562 & 96 & 547 \\
\hline $\operatorname{lgM}(\mathrm{mg} / \mathrm{dl})$ & 63 & 64 & 44 & 29 & 97 & 66 & 65 & 46 & 76 & 42 & 28 & 5 & 114 \\
\hline Phytohemagglutinin & $\downarrow \downarrow$ & $\downarrow$ & $\downarrow \downarrow$ & $\downarrow \downarrow$ & $\downarrow \downarrow$ & $\downarrow \downarrow$ & $\downarrow \downarrow$ & $\downarrow$ & $\sim \sim$ & $\sim \sim$ & $\downarrow$ & $\sim \sim$ & $\downarrow \downarrow$ \\
\hline Concanavalin A & $\downarrow \downarrow$ & $\downarrow \downarrow$ & $\downarrow \downarrow$ & $\downarrow \downarrow$ & $\downarrow \downarrow$ & ND & $\downarrow \downarrow$ & $\downarrow$ & $\sim$ & $\sim \sim$ & $\downarrow \downarrow$ & $\sim \sim$ & $\downarrow \downarrow$ \\
\hline Pokeweed mitogen & $\sim \sim$ & $\downarrow \downarrow$ & $\downarrow \downarrow$ & $\downarrow$ & $\downarrow \downarrow$ & ND & $\downarrow \downarrow$ & $\downarrow$ & $\sim$ & $\sim \sim$ & $\downarrow \downarrow$ & $\sim$ & $\downarrow \downarrow$ \\
\hline CTL (lytic units) & $\leq 0.01$ & ND & $\leq 0.01$ & $\leq 0.01$ & $\leq 0.01$ & $\leq 0.01$ & 19.9 & $\leq 0.01$ & $\leq 0.01$ & $\leq 0.01$ & $\leq 0.01$ & 7.7 & $\leq 0.01$ \\
\hline NK (lytic units) & $\leq 0.01$ & $\leq 0.01$ & $\leq 0.01$ & $\leq 0.01$ & $\leq 0.01$ & $\leq 0.01$ & 0.68 & $\leq 0.01$ & $\leq 0.01$ & $\leq 0.01$ & $\leq 0.01$ & 0.06 & $\leq 0.01$ \\
\hline
\end{tabular}

$\downarrow \downarrow$. severely decreased $(0-25 \%$ of average control); $\downarrow$, decreased (>25-75\% of average control) ; , normal ( $>75 \%$ of average control). Normal values for CTL activity $>10$ lytic units, NK activity 4-20 lytic units. ALC, absolute lymphocyte count.

$408-5,850 / \mathrm{mm}^{3}$ for 11 months to 6 years of age).

There was no consistent abnormality of immunoglobulin levels detected. Most patients had normal levels for age; however, there were individual patients with either decreased immunoglobulin levels, decreased $\lg G 2$, or elevated $\operatorname{Ig} A$ or IgE levels.

Functional assays demonstrated profoundly abnormal immune function. Proliferative responses to mitogenic stimulation were decreased $(<75$ to $>25 \%$ average adult control of the day) to severely decreased $(<25 \%$ average control) in $85 \%(10 / 13)$ of the patients. Cytotoxic assays included NK cell function and CTL. NK function was virtually absent in all 13 patients. CTL was decreased $(11 / 12)$ to absent $(10 / 12)$ in most patients.

\section{DISCUSSION}

HLH is a fulminant, life-threatening hemophagocytic syndrome characterized by fever, pancytopenia, hypertriglyceridemia, hypofibrinogenemia, and infiltration of vital organs by lymphocytes and non-Langerhans histiocytes. While the etiology of HLH is unknown, it appears most likely that there is an underlying abnormality in immunoregulation that contributes to the lack of control of an exaggerated immune response. The immune dysregulation may be primary, as in the inherited FHL. or, as is often the case in VAHS/IAHS, secondary $(2,10-12)$. The most consistent immunologic abnormality previously described in patients with HLH has been impairment of NK function (13-16) with normal numbers and phenotype of NK cells (17). Few studies are available that have addressed more extensive cellular and humoral immunologic defects in patients with HLH at the time of diagnosis. Comprehensive immunologic evaluation was undertaken in 13 sequential patients diagnosed with HLH to identify immune abnormalities that are characteristic of HLH. Our results show that while humoral immunity is essentially intact. cellular function is abnormal in most. Identification of characteristic immunologic abnormalities, specifically depression or absence of cytotoxic responses. can assist in confirming a diagnosis of HLH and potentially may be useful in early diagnosis prior to onset of the hemophagocytic process in FHL.

The FHL Working Group of the Histiocyte Society has recently proposed diagnostic criteria that have greatly helped in establishing a diagnosis of HLH based on clinical grounds with histologic and laboratory support. The sine qua non of HLH remains the histologic demonstration of benign, non-Langerhans histiocytosis associated with hemophagocytosis. Bone marrow is the most accessible area to detect this feature; however, initial bone marrow biopsies often fail to demonstrate histiocytes or hemophagocytosis, thus delaying the diagnosis. Repeated bone marrow biopsies will eventually show increased numbers of histiocytes, lymphocytes, and hemophagocytosis in most patients. It is important to note that the lack of a positive bone marrow test does not rule 
out the diagnosis. Two patients in this series who met most of the diagnostic guidelines, yet failed to have a confirmatory premortem biopsy, were found on autopsy to have extensive lymphohistiocytic hemophagocytosis in their organs. While the proposed clinical and laboratory guidelines for making this diagnosis have greatly improved the ability to establish a diagnosis, additional laboratory characterization can assist in confirming the diagnosis, especially in patients without biopsy confirmation.

Our immunologic assessment showed that most patients with HLH have normal quantitative serum immunoglobulin levels with no consistent pattern of immunoglobulin deficiency being identificd. Specific antibody responses were not assessed in most due to young age or lack of immunizations. Phenotypic analysis of lymphocyte subsets showed the majority to have surprisingly normal absolute lymphocyte counts and normal distribution of mature $T$ cell subsets. The $T$ helper/T suppressor ratio (CD4/CD8) was normal in all patients. The expression of NK eell markers (CD16, CD56, CD57) also was normal. B eell numbers, as determined by CDI9 expression, were frequently decreased for age. This latter finding has not previously been reported.

NK function was found to be markedly decreased to absent in all 13 patients. The consistent finding of severely deficient NK function makes this a useful confirmatory test in HLH. Of particular interest is that (hediak-Higashi syndrome, a congenital immunodeficiency disorder that includes impaired NK function. frequently results in a fatal hemophagocytic process (accelerated phase) associated with Epstein-Barr virus infection that is identical to IILII. We, as others have reported (14), have observed two patients recover normal NK function and one other patient improved NK function during remission, suggesting that this cellular dysfunction may be a secondary event and not a primary immunologic abnormality.

Cytotoxic T cell function was severely depressed in most of our paticnts. This finding confirms an carlicr report from our institution where three of three patients had decreased to absent CTL (18). Arico et al. (15) reported four patients with HLH that not only had decreased cytotoxic function by NK cells, but also defective killing lymphokine-activated killer cells and antibody-mediated ecllular cytotoxic cells. Collectively, data suggest that patients with HLH experience global dysfunction of cytotoxic cells at least during the acute phase of their disorder. Since the majority of our patients were studied prior to receiving any chemotherapy, this dysfunction is not the result of therapy. Cytotoxic $T$ cell dysfunction is a characteristic feature of HLH and may be an additional confirmatory diagnostic test. Unclear at this time is whether this finding rep- resents a predisposing immunologic abnormality or secondary immune dysfunction.

Proliferation of peripheral blood mononuclear cells in response to mitogenic stimulation by phytohemagglutinin, concanavalin $\mathrm{A}$, and pokeweed mitogen was decreased in the majority of the patients. Ladisch et al. (19) and McClain et al. (18) have previously reported decreased mitogenic responses in a limited number of patients and suggested that the decreases were inversely proportional to the elevation of plasma triglycerides. While our findings confirm the decreased proliferative responses, we do not find any relation to triglyceride levels (data not shown). Persistent $T$ cell activation and overproduction of cytokines have been implicated as contributory factors in the pathophysiology of HLH. Abnormal lymphoprolification in vitro may be secondary to a refractory state of the circulating $T$ cells associated with chronic activation. Patients with active discase have been reported to have increased class II expression by $\mathrm{T}$ eclls, marked elevation of serum soluble interleukin-2 receptors (20), increased soluble CD8 (21), as well as elevated neopterin levels $(22,23)$, all markers of $T$ cell activation. Serum levels of interferon- $\gamma$, interleukin-6, and tumor necrosis factor are also elevated. and increased levels correlate with disease activity (2l). Clinically, patients respond favorably to immunosuppressive agents with symptomatic and laboratory remission of their discase. We recently reported immunosuppressive therapy as a suecessful alternative to chemotherapy as maintenance therapy (6).

Our findings clearly demonstrate that patients with HLH have consistent and significant abnormalities in immune function. We demonstrate that detection of decreased CTL, decreased mitogen responses, and absent NK function are characteristic features of HLH. The presence of essentially normal $\mathrm{T}$ lymphocyte numbers, subsets, and immunoglobulin levels may be useful in excluding several well characterized primary immune deficiencies that can have similar clinical presentations in infancy. We propose that in addition to the diagnostic guidelines proposed by the FHL Study (iroup, abnormal immunologic function including NK. ('TL. and mitogen-induced proliferation be considered as additional supportive laboratory criteria useful in confirming a diagnosis of HLH. These findings do not necessarily define an underlying primary immune defect. Further studies are needed to determine whether functional studies can be used for early diagnosis or whether they may be helpful in discriminating FHL from VAHS/IAIIS in young children presenting HLH and lacking a positive family history.

Acknowledgment: Dr. Egeler conducted this work during a visiting fellowship sponsored by the Royal Dutch Academy of Arts and Sciences. 


\section{REFERENCES}

1. Farquhar JW. ('aireaux AF. Familial hemophagocytic reticulosis. Arch Dis ( hild 1952:27:519 25.

2. Risdall RJ. McKenna RW. Nesbit MI: et al. Virus-associated bemophagocytic syndrome: a benign histiocytic proliferation distinct from malignant histiocytosis. (ancer 1979;44:992-1002

3. Henter J-I, Soder O. Ost A. I:linder (j. Incidence and elinical features of familial hemophagocytic lymphohistiocytosis in Sweden. Acta Pardiat Siand 1991:80:428-35.

4. Ambruso DR. Hays T. Zwartjes WJ. Tubergen D. Favara B. Successful treatment of lymphohistiocytic reticulosis with phagocytosis with epipodophyllotoxin VP16-213. (ander 1980:45:2516 20).

5. Henter II. Elinder G. Soder O. Ost A. Successful induction with chemotherapy including teniposide in familial erythrophagocytic lymphohistiocylosis. Lancer 1986;2:1402.

6. Loechelt BJ. Egeler RM. Iilipovich AII. Jyonouchi H. Shapiro RS. Immunosuppression: an alternative maintenance therapy for familial hemophagocytic lymphohistiocytosis (FHL) preliminary results. Med Pediatr ()ncol 1994:22:3258.

7. Henter JI, Elinder G. Ost A. FHI. Study (iroup of the Histiocylo Society. Diagnostic guidelines for hemophagocytic lymphohistiocytosis. Semin (Once)/ 1091;18:20 33

8. Janka (if:. Familial hemophagocytic lymphohistiocytosis. Eu If Pediall $1983: 140: 22130$

9. Stark 13. Cohen IJ, Pecht M. et al. Immunologic dystegulation in a patient with familial hemophagocytic lymphohistiocytosis. (ance' 1987:60:2629 36 .

10. Zuazu JP. Duran JW. Julia AF. Hemophagocytosis in acute hrucellosis. N Engl J Med 1979:301:1185 6

11. Risdall RJ, Brunning RD, Hernandez JI, Gordon DH. Bacteria-associated hemophagocytic syndrome. Cance' 1984:54:2968-72.

12. Jaffe ES. Costa J. Fauci AS. Cossman J. Tsokos M. Malignant Jymphoma and erythrophagocytosis simulating malignant histiocytosis. $A m . / M c^{\circ} / 1983: 75: 7419$.
13. Holtman H, Janka Gil:, Weidner E, Vife R. Impaired natural killer cell function in familial hemophagocytic lymphohistiocytosis. $/ m$ munobiologe 1982:162:364 71 .

14. Perez N. Virelizier JL, Arenazama-Seisdedos l: Fischer $A$, Griscelli $C$. Impaired natural killer activity in lymphohistiocytosis syndrome. I Pediall 1984:104:469 573.

15. Arico M. Nespoli L. Maccario R. et al. Natural cytotoxicity impairment in familial hemophagocytic lymphohistiocytosis. frch Dis ( Hild 1988:63:292 6

16. Kataoka Y. Todo S. Rorioka Y. et al. Impaired natural killer activity and expression of interleukin-2 receptor antigen in familial crythrophagocytic lymphohistiocytosis. (ancor 1990):65:1937 41 .

17. Eife R. Jankal (iE: Belohradsky BH, Holtmann H. Natural killer cell function and interferon production in familial hemophagocyt

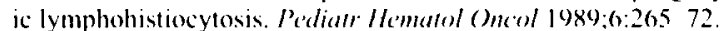

18. McClain K. Gelerz R. (iricrson H. Purtilo D. Filipovich A. Virusassociated histiocytic proliferations in children. Frequent association with lipstein Barr virus and congenital or acquired immunodeficiencies. Am J Pediatr /

19. Ladisch S. Poplack D(j. Holiman B. Blases RM. Immunodeficiency in familial hemophagocytic lymphohistiocytosis. Lamcet 1978:1 5813

20. Komp DM, MeNamara J, Buckley P. I:levated soluble interleuhin2 receptor in childhood hemophagoeytic histiocytic syndromes Blood 1989:73:2128. 32

21. Henter JI. Flinder G, Soder O, Hansson M, Andersison B. Andersson U. Hypercytokinemia in familial hemophagocytic lymphohistiocytosis. Blood 1991:78:2918 22.

22. Howells DW. Strobel S. Smith I. Levinsky R.J. Hyland K. Central nervous system involvement in the erythrophagocytic disorder of infancy: the role of cercbrospinal fluid neopterins in their differential diagnosis and clinical management. Pediar Re's 1990:28: 116.99.

23. Henter JI. Elinder G. Cerebromeningeal hemophagocytic lympholistiocytosis Lance 1992:1339:1047 